\title{
A JUDICIAL BIOGRAPHY
}

William Wayne Justice 


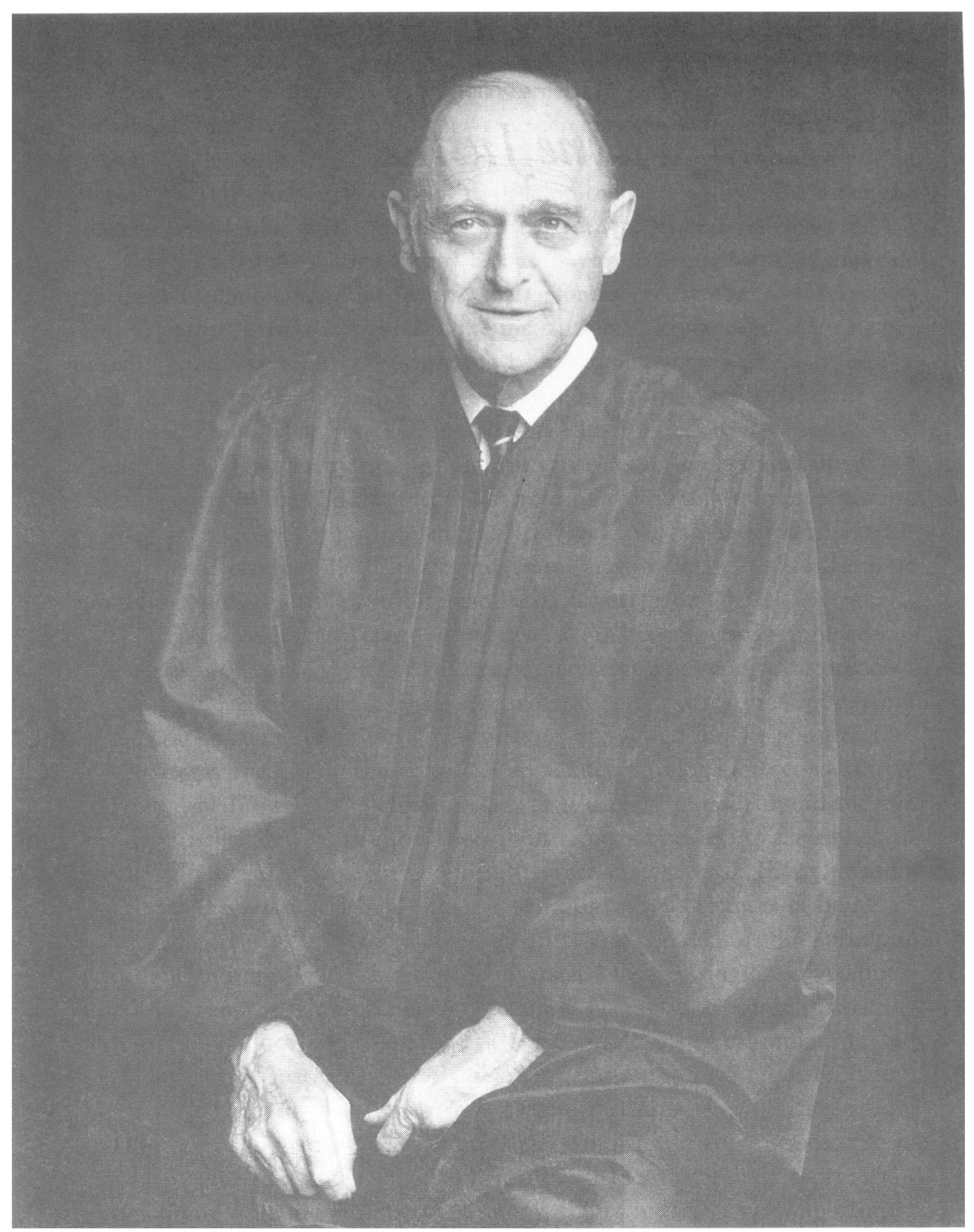

Photo by John Katz, Dallas 


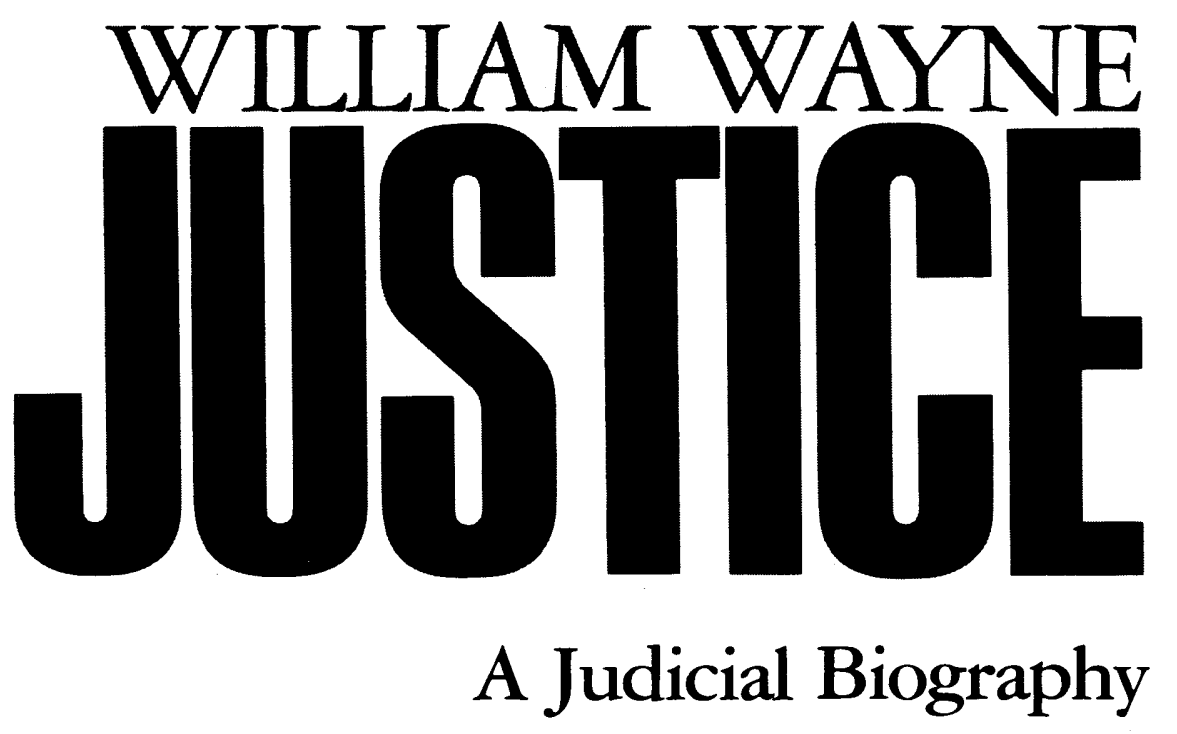

By Frank R. Kemerer

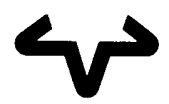

UNIVERSITY OF TEXAS PRESS, AUSTIN 


\section{For Barbie, whose support and encouragement were instrumental to the completion of this book.}

Publication of this work was made possible in part by support from the J. $E$. Smotbers, Sr., Memorial Foundation and the National Endowment for the Humanities.

Epilogue copyright $(0) 2008$ by the University of Texas Press Copyright $(\mathcal{C}$ x99 I by the University of Texas Press

All rights reserved

Printed in the United States of America

First edition, I991

First paperback printing, 2008

Copyright (C) 2008 by the University of Texas Press

All rights reserved

Printed in the United States of America

First edition, 2008

Requests for permission to reproduce material from this work should be sent to: Permissions

University of Texas Press

P.O. Box 78 I9

Austin, TX 78713-7819

www.utexas.edu/utpress/about/bpermission.html

(0) The paper used in this book meets the minimum requirements of ANSI/NISO Z39.48-I992 (RI997) (Permanence of Paper).

The Library of Congress has catalogued the hardcover edition as follows:

\section{Library of Congress Cataloging-in-Publication Data}

Kemerer, Frank R.

William Wayne Justice : a judicial biography / by Frank R. Kemerer. — Ist pbk. ed. p. $\mathrm{cm}$.

Includes index.

ISBN 978-0-292-7 1905-7 (pbk. : alk. paper)

I. Justice, William Wayne, r920- . 2. Judges-Texas-Biography. 3. JudgesUnited States-Biography. 4. Political questions and judicial power-Texas.

5. Political questions and judicial power-United States. I. Title.

$\mathrm{KF} 373 . \mathrm{J} 87 \mathrm{~K} 46 \quad 2008$

$347.73^{1} 14092-\mathrm{dc} 22$

[B] 
Jack and Doris Smothers Series in Texas History, Life, and Culture, Number 22 
